\title{
Complete Columbian mammoth mitogenome suggests interbreeding with woolly mammoths
}

\author{
Jacob Enk ${ }^{1 *}$, Alison Devault ${ }^{1}$, Regis Debruyne ${ }^{1,2}$, Christine E King ${ }^{1}$, Todd Treangen ${ }^{3}$, Dennis O'Rourke ${ }^{4}$ \\ Steven L Salzberg ${ }^{3}$, Daniel Fisher ${ }^{5}$, Ross MacPhee ${ }^{6}$ and Hendrik Poinar ${ }^{{ }^{*}}$
}

\begin{abstract}
Background: Late Pleistocene North America hosted at least two divergent and ecologically distinct species of mammoth: the periglacial woolly mammoth (Mammuthus primigenius) and the subglacial Columbian mammoth (Mammuthus columbi). To date, mammoth genetic research has been entirely restricted to woolly mammoths, rendering their genetic evolution difficult to contextualize within broader Pleistocene paleoecology and biogeography. Here, we take an interspecific approach to clarifying mammoth phylogeny by targeting Columbian mammoth remains for mitogenomic sequencing.

Results: We sequenced the first complete mitochondrial genome of a classic Columbian mammoth, as well as the first complete mitochondrial genome of a North American woolly mammoth. Somewhat contrary to conventional paleontological models, which posit that the two species were highly divergent, the M. columbi mitogenome we obtained falls securely within a subclade of endemic North American M. primigenius.

Conclusions: Though limited, our data suggest that the two species interbred at some point in their evolutionary histories. One potential explanation is that woolly mammoth haplotypes entered Columbian mammoth populations via introgression at subglacial ecotones, a scenario with compelling parallels in extant elephants and consistent with certain regional paleontological observations. This highlights the need for multi-genomic data to sufficiently characterize mammoth evolutionary history. Our results demonstrate that the use of next-generation sequencing technologies holds promise in obtaining such data, even from non-cave, non-permafrost Pleistocene depositional contexts.
\end{abstract}

\section{Background}

Conventional paleontological models [1-4] of North American mammoth evolution posit that at least two species occupied the continent during the late Pleistocene (150,000 to 10,000 years ago: Mammuthus primigenius (woolly mammoths (WMs)) evolved in Eurasia and immigrated to North America in the late Pleistocene, whereas Mammuthus columbi (Columbian mammoths (CMs)) evolved locally from an earlier Pleistocene immigrant ancestor (Mammuthus meridionalis [1,2] or Mammuthus trogontherii [3,4]). The species are morphologically differentiated by physical size (CMs were some 25\% taller than WMs [5]), molar complexity (CMs displayed more 'primitive' crown height

\footnotetext{
* Correspondence: enkjm@mcmaster.ca; poinarh@mcmaster.ca 'McMaster Ancient DNA Centre, Department of Anthropology, McMaster University, 1280 Main Street West, Hamilton, Ontario L8S 4L9, Canada Full list of author information is available at the end of the article
}

and lamellar configuration), and skull morphology (CMs possessed a more downturned mandibular symphysis and more laterally oriented tusk alveoli) $[1,5]$. Some of these traits are considered adaptations to their disparate habitats: WMs inhabited cold and arid periglacial regions, while CMs inhabited the temperate regions of the southern latitudes. Continental populations of both species went extinct during the Pleistocene-Holocene transition some 10,000 years ago.

Recent paleontological reconsiderations [6-8] and mitochondrial DNA (mtDNA) phylogeographic studies of predominantly Beringian mammoths [9-13] reveal a complex evolutionary history (Figure 1a). Their populations harbored diverse genetic lineages, two of which, haplogroups $\mathrm{A}$ and $\mathrm{C}$, were endemic to Eurasia and North America, respectively. Certain population dynamics - including major immigration/replacement events and regional genetic introgression - have been offered as explanations
C Biomed Central

() 2011 Enk et al.; licensee BioMed Central Ltd. This is an open access article distributed under the terms of the Creative Commons Attribution License (http://creativecommons.org/licenses/by/2.0), which permits unrestricted use, distribution, and reproduction in any medium, provided the original work is properly cited. 


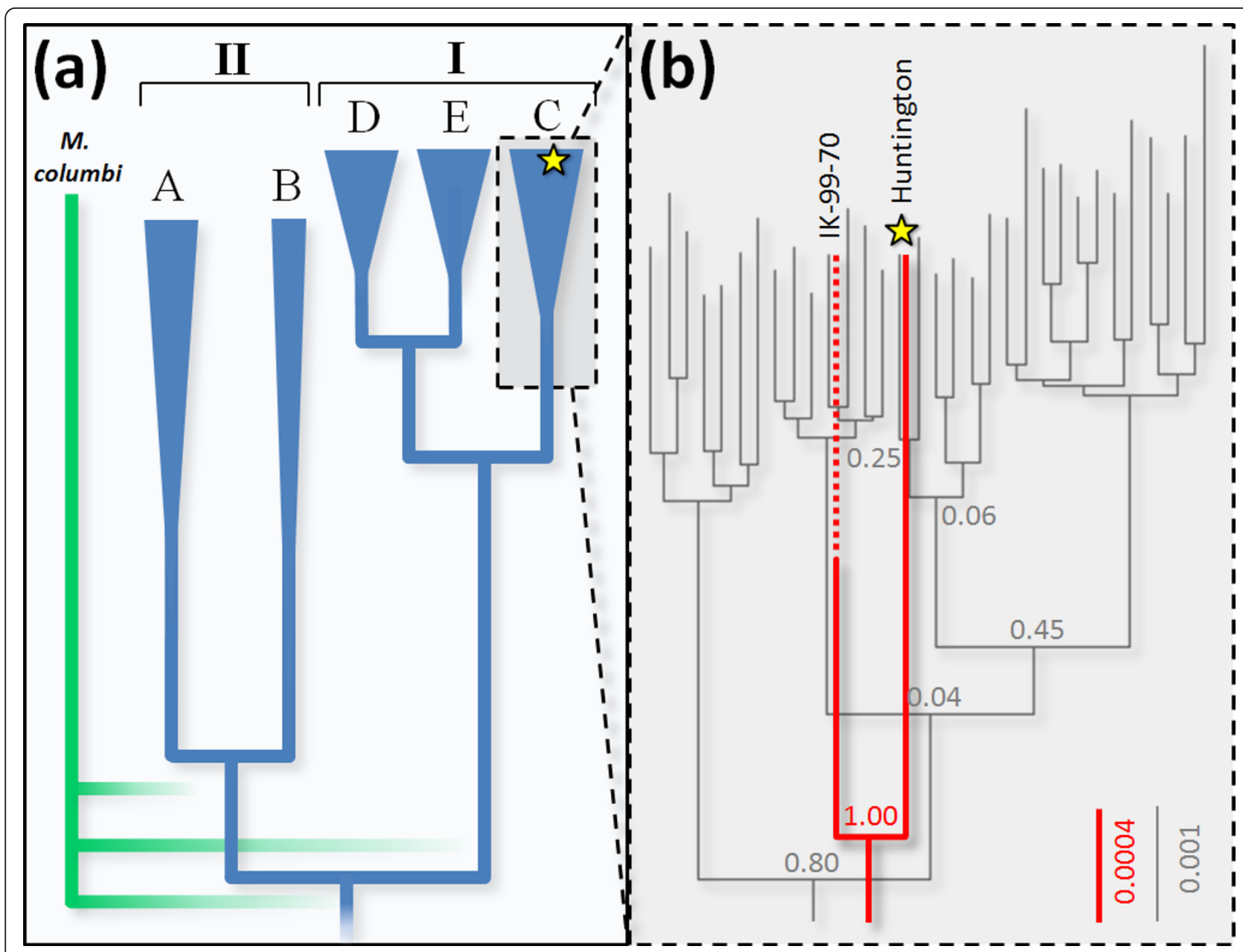

Figure 1 Mammoth mitochondrial DNA cladograms. (a) WM lineages (blue) are summarized from previous studies [9-11] with clades indicated and haplogroups labeled at the tips. Hypothetical CM lineage positions (green) are expected positions derived from strict interpretations of paleontological models that posit the two species were separate since the early Pleistocene. The multiple node positions reflect the general uncertainty surrounding the chronology and identity of the WM lineage common ancestor. The position of WM haplogroup B is poorly resolved, exhibiting deep common ancestry with the other haplogroups. Haplogroups A and C are endemic to Eurasia and North America, respectively; haplogroups B, D, and E occur on both continents. Radiocarbon chronologies indicate that haplogroup A went extinct approximately $35,000{ }^{14} \mathrm{Cya}$, and clade I by approximately 3,200 ${ }^{14} \mathrm{Cya}$. Calculated MRCA ages for all nodes yield wide confidence intervals. (b) Our estimated mtDNA cladograms of haplogroup $C$ are depicted using two datasets: the black cladogram and associated scale and posterior probabilities (parameter set 1b, Figure S4 in Additional file 3) are estimated from $743 \mathrm{bp}$ for which several dozen mammoths have been sequenced, whereas the red cladogram and associated scale and posterior probabilities (parameter set 4b, Figure S8 in Additional file 3) are estimated from full mitochondrial genomes, for which only one other haplogroup C mammoth has been sequenced. Each tip in the black cladogram represents a haplotype. M. columbi (haplotype C32) as represented by the Huntington Mammoth is indicated with a yellow star. Scale units are substitutions per site.

for this complexity [10,11], but its precise origins have proven difficult to define within the broader context of Pleistocene biogeography and paleoecology. This is the case for at least two reasons: first, key coalescent dates remain difficult to measure, in large part due to lack of sequence breadth and methodological shortcomings $[14,15]$; and second, almost nothing is known about the mtDNA phylogeny of Mammuthus beyond Beringian late Pleistocene mammoths (and thus probably exclusively $M$. primigenius). One potential solution to both problems - and means to hone conceptions of Pleistocene mammoth evolution in general - is to sequence DNA from one or more closely related but distinct mammoth species and use it as a temporal and taxonomic calibration tool within the mammoth gene tree. Owing to their apparently separate evolutionary history (Figure 1a) and reasonably welldated recent divergence from WMs about 1 to 2 million years ago [16], CMs are excellent candidates for this role. To this end we targeted CM remains for mitogenomic sequencing. 
We selected the Huntington Mammoth [17] for this purpose on account of its secure morphological identification, direct radiocarbon date $\left(11,220 \pm 110{ }^{14} \mathrm{Cya}\right.$ (radiocarbon years ago), exceptional biomolecular preservation [18] and geographic provenience (Fairview, UT, USA), far south of the Wisconsinan glaciers. Typical strategies for DNA sequencing of paleontological specimens would employ a pre-sequencing targeted enrichment approach, through the use of either laborintensive PCR or hybridization techniques [19]. However, following serial extraction and library preparation of our specimen, a quantitative PCR-based metric projected a sufficient ratio of target to non-target DNA to warrant a shotgun-based metagenomic sequencing approach, for which we employed the Illumina platform (see Materials and methods; Additional file 1).

\section{Results and Discussion}

Of the over 27 million reads longer than $50 \mathrm{bp}$ obtained from the Huntington sample library, between 6,000 and 9,000 (0.02 to $0.03 \%)$ mapped to a WM reference mitogenome [GenBank: NC007596.2] [20] depending on software assembly parameters (Table S3 in Additional file 2). This provided an average unique read depth of approximately $23 \times$ for the entire mitochondrial genome, excluding the VNTR region (positions 16,157 to $16,476)$. Roughly 2 million reads also mapped to the African elephant (Loxodonta africana) nuclear genome, providing approximately $0.03 \times$ coverage of the entire nuclear genome of the animal, and bringing the total likely mammoth DNA read count to approximately 7\% of all sequences. Such a proportion of total endogenous DNA is consistent with taphonomic models for DNA preservation in temperate burial contexts [21], as well as experimental data from other non-permafrost remains $[22,23]$. The coverage depth ratio we observe between mitochondrial and nuclear reads (approximately $800 \times$ ) also falls within the range estimated in other mammoth specimens $(245$ to $17,000 \times[24])$. This low nuclear read coverage depth also lends evidence that potential Numts make no significant contribution to the consensus generated from the mitochondrial assembly.

To ensure the authenticity of the mitogenome sequence, we amplified, cloned and sequenced PCR products of WM haplotype-defining regions of the cytochrome $b$ gene and hypervariable region from multiple extractions of the Huntington mammoth in two separate ancient DNA facilities. These all yielded consensus sequences $100 \%$ identical to the shotgun consensus where they overlapped. Furthermore, we sequenced the same loci from PCRs of another securely identified $M$. columbi (the Union Pacific mammoth, University of Wyoming 6368, found near Rawlins, WY, USA $[25,26]$ ), which yielded identical sequences to those acquired for
Huntington. Finally, to control for ascertainment bias in assembly of the whole mitogenome, we mapped the Illumina sequencing reads to an Asiatic elephant (Elephas maximus) mitogenome [GenBank: DQ316068] and obtained a $99.98 \%$ identical consensus sequence where it overlapped with the WM assembly consensus. Thus, we are confident that the final Huntington mammoth mitogenome sequence derives from the genuine endogenous mtDNA of the animal.

Bayesian phylogenetic analysis demonstrates that the Huntington mammoth mitogenome is largely indiscernible from those of endemic North American WMs (Figure 1b). For all model and parameter variants (Table S7 in Additional file 2, Figures S3, S4, S5, S6, S7, and S8 in Additional file 3 ), the sequence sorts securely within haplogroup $C$, a subclade additionally represented by dozens of WMs from Alaska and the Yukon [11]. To test for this relationship at the entire mitogenomic level, we also sequenced the first complete mitogenome of a WM from this haplogroup (IK-99-70, from the Alaskan North Slope, USA), which confirmed Huntington's phylogenetic position within haplogroup C (Figure 1b).

At first glance, these results would suggest that, contrary to a strict interpretation of traditional paleontological models for their evolution, CMs and WMs did not descend from populations that were wholly separate since the early Pleistocene. One interpretation could be that mitochondrial haplogroup $\mathrm{C}$ corresponds to descendants of immigrant mammoth populations that ultimately gave rise to M. columbi. But without expansion, this interpretation would fail to explain why haplogroup $\mathrm{C}$ belongs to mammoths with both CM and WM morphologies. Indeed, certain paleontological interpretations have already suggested that CMs and WMs were more closely related than typically thought, even 'geoclinal or chronoclinal variants' [27] descending from a very recent common ancestor. We find that our results also warrant consideration of an alternative scheme, one that operates within existing paleontological models but that accommodates incomplete reproductive barriers between CMs and WMs during some period(s) of their evolutionary history.

mtDNA phylogenies are often inconsistent with species phylogenies [28], especially for populations with sex-biased dispersion and breeding patterns. This is particularly true for extant elephants [29,30], which exhibit male-mediated gene flow between matriarchal herds, rendering their mtDNA phylogenies incomplete representations of breeding history. For example, Asiatic elephant and WM populations both harbor(ed) at least two highly divergent mitochondrial lineages without corresponding morphological differentiation [9-11,31]. Between CMs and WMs, we observe the opposite situation, where their morphological distinction appears to 
have little mitochondrial genetic correlation. One potential explanation for this is that incomplete lineage sorting (ILS) resulted in the maintenance in CM populations of what ultimately became more WM-like mitochondrial lineages. However, if this were the case, we would expect the CM-WM most recent common ancestor (MRCA) to be positioned much deeper in the cytochrome $b$ /hypervariable region phylogeny than observed. Our and previous [11] dual-calibrated estimates for the MRCA for the entirety of haplogroup C dates to the middle Pleistocene (Table S7 in Additional file 2), with the CM-WM MRCA necessarily occurring much more recently, long after their purported species divergence. That said, the haplogroup $\mathrm{C}$ full mitochondrial dataset is too small to completely rule out ILS during CM-WM speciation as a plausible explanation.

At present, however, we suspect that hybridization between CMs and WMs may be a more parsimonious explanation for our observations. Under one conception, haplogroup $C$ could have been a predominantly CM haplogroup that introgressed into WM populations, at such a frequency that it came to dominate the North American mitochondrial gene pool of that species. The fact that both CMs sequenced here are haplogroup $\mathrm{C}$ would lend some support to this hypothesis. Another possibility is that introgression occurred in the opposite direction, such that WM-typical haplogroup C introgressed into $\mathrm{CM}$ populations (Figure 2a). From a behavioral perspective, this configuration is perhaps more likely, especially in light of phenomena documented in extant African forest (Loxodonta cyclotis) and savanna (L. africana) elephants (Figure $2 \mathrm{~b}$ ). These living species are morphologically distinct and deeply divergent at many nuclear loci [32-35], but are known to interbreed at forest-savanna ecotones [36,37]. The result is 'cytonuclear dissociation' [38] between genomes in hybrid individuals, such that forest-typical mitochondrial haplotypes occur at low frequency in savanna populations. Hypothetically, this is driven by savanna males reproductively out-competing physically smaller forest males [38], producing unidirectional backcrossing of hybrid females into savanna populations. Since mammoths

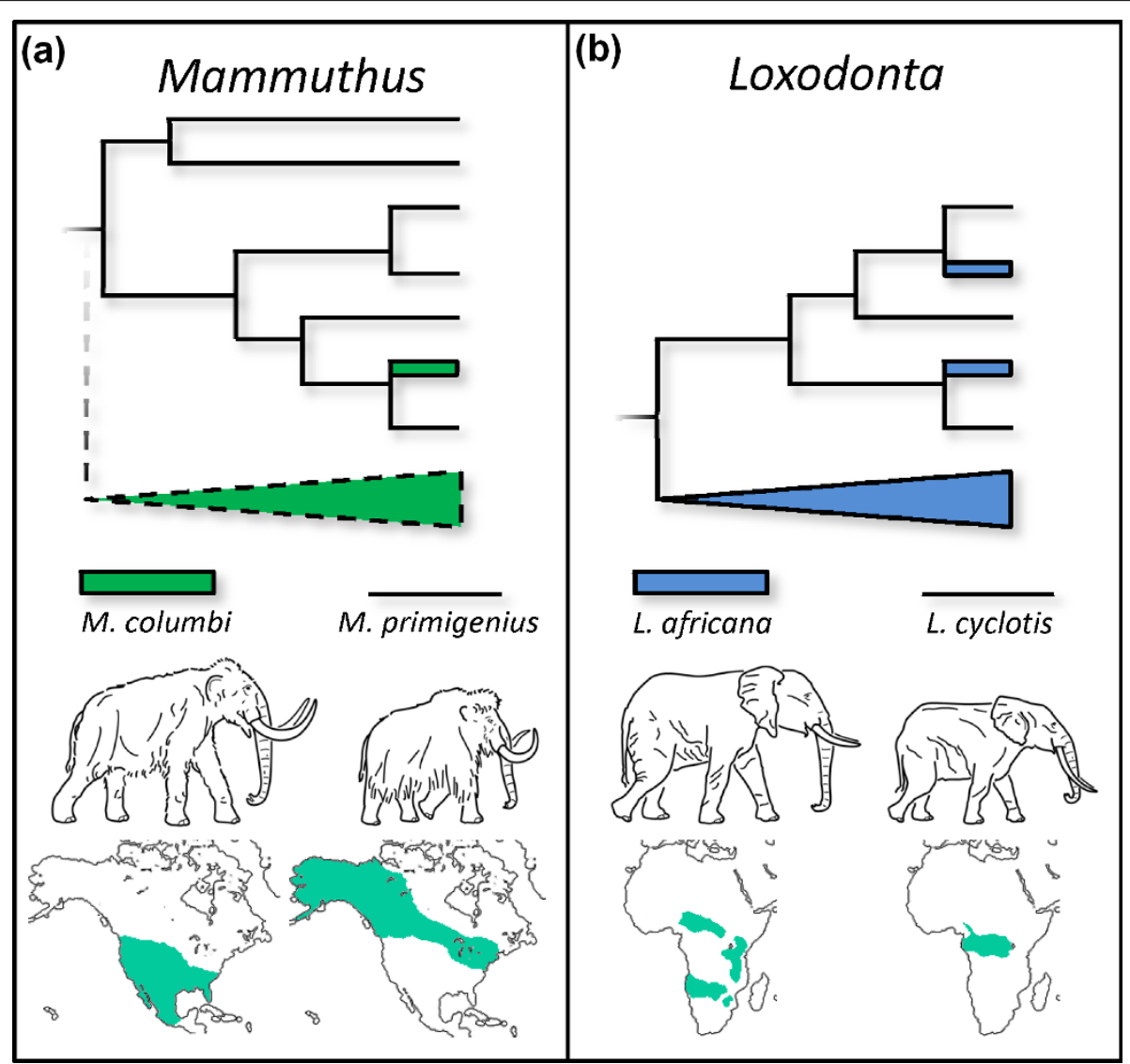

Figure 2 Schematic representation of elephantid mtDNA phylogenies under introgression scenarios. (a,b) Hypothetical mammoth $(b)$ (this study) and observed African elephant (a) [38] cladograms, with male body size comparisons and predominant geographic ranges of the species indicated. Solid lines represent observed data; dashed lines represent predicted but presently unobserved lineages under an $M$. primigenius-M. columbi introgression hypothesis. 
were probably very similar to modern elephants in social and reproductive behavior [4,27], it is conceivable that WMs and the physically larger CMs engaged in a similar dynamic when they encountered each other. Indeed, hybridization between CMs and WMs has already been suggested by others [39], and genetic exchange may explain mammoths bearing CM-WM intermediate morphologies. Such mammoths are frequently found in areas where CMs and WMs overlapped in time and space, such as the Great Lakes region [2]. Some of these apparent intermediates have been formally named (for example, Mammuthus jeffersonii), but their taxonomic identity is questionable. Indeed, the large number of synonyms currently registered for North American mammoths [40] is at least partly a function of efforts by earlier systematists to come to grips with the large amount of morphological variation expressed within Mammuthus (or Elephas). Although the Huntington mammoth exhibits no such morphological intermediacy and was found quite distant from the documented WM range, its status as a genetic hybrid would not be inconsistent with the modern analog: forest haplotype-bearing savanna elephants can be found several thousands of kilometers from modern ecotones, bearing no phenotypic indication of hybridism [38].

Both the ILS and introgression hypotheses discussed above provide straightforward testable predictions. First, under a WM-CM introgression scenario, some presently unidentified and distinct mitochondrial haplogroup should characterize a significant percentage of CM lineages, rendering their mitogenomes polyphyletic, as they are in $L$. africana (Figure 2). While we also observe a likely $\mathrm{C}$ haplotype in short sequences from one other well-identified terminal Pleistocene $M$. columbi, only a broad populationlevel survey of CM genetic diversity can rigorously test this prediction. Second, under the introgression hypothesis, CMs with WM-type mitogenomes should possess nuclear genes that are significantly more divergent from WMs than all haplogroup $\mathrm{C}$ mammoths are from each other. On the other hand, an ILS scenario would predict that CM and WM nuclear genes should show a similar degree of divergence as is detected between haplogroup $\mathrm{C}$ mitogenomes. Though we did recover several million nuclear sequences from the Huntington DNA library, the very low coverage depth provided by these reads is not sufficient for reliable nuclear divergence estimates between CMs and WMs. However, we anticipate that targeted enrichment techniques [41,42] prior to high-throughput sequencing will provide the necessary coverage depth to test these hypotheses in the near future.

\section{Conclusions}

The revealed mitochondrial phylogenetic position of $M$. columbi does not immediately clarify complexities and chronological uncertainties previously observed in mammoth mtDNA phylogeny. Instead, it emphasizes that the unique reproductive behavior of elephantids necessitates a multi-genomic approach to characterizing their evolutionary history, as has been so effectively used in studies of living elephants. Their very recent mitochondrial common ancestry strongly suggests that CMs and WMs interbred at some point, most likely post-dating their morphological divergence, and in a fashion that confounds simple correlation of mtDNA phylogeny to evolutionary models derived from mammoth morphology alone. However, the precise mode and setting of genetic interchange between WMs and CMs are elusive, and therefore all hypotheses explaining our observations warrant testing. The possibility that hybridization explains our data is particularly tantalizing, since in many animals, interspecific hybridization accompanies population displacement and/or expansion resulting from habitat reconfiguration $[43,44]$. Thus, interbreeding between extinct late Pleistocene taxa - especially keystone herbivores like mammoths - could serve as an indicator of major ecological events, including those surrounding the megafaunal extinctions. Our results demonstrate that the use of next-generation sequencing technologies holds promise in rigorously testing such hypotheses using full ancient genomic data, even from non-cave, non-permafrost Pleistocene depositional contexts.

\section{Materials and methods Samples}

We included two M. columbi (Columbian mammoths) and one Mammuthus sp. in the sample set, stored at room temperature at our laboratory.

\section{Huntington mammoth - M. columbi}

College of Eastern Utah Museum CEUM897 is associated with numerous radiocarbon dates, though 11,220 $\pm 110{ }^{14} \mathrm{Cya}$ is probably most accurate [17]. It was discovered in 1988 during excavation of a stream for dam construction, at the southeast end of what is now Huntington Reservoir, just east of Fairview, Utah, USA. This $60+$ year old bull is exceptionally well preserved, and exhibits the classic character suite of his species, including low molar lamellar frequency (Figure S1 in Additional file 3), broadly divergent tusk alveoli, a markedly downturned mandibular symphysis, and tremendous body size. We used tusk fragments for the shotgun sequencing, and both tusk and bone samples for PCR and Sanger sequencing.

\section{Union Pacific mammoth - M. columbi}

University of Wyoming UW6368 is dated to $11,280 \pm$ $350{ }^{14}$ Cya $[25,26]$. It was discovered in 1960 by a gas well-drilling crew while drag-lining a spring site southwest of Rawlins, Wyoming, USA. Fragments of molar teeth were used for PCR and Sanger sequencing. 


\section{MPC IK-99-70 - Mammuthus sp}

Specimen found in the Upper Ikpikpuk River $\left(70^{\circ} 47^{\prime} \mathrm{N}\right.$, $\left.154^{\circ} 25^{\prime} \mathrm{W}\right)$ on the Alaskan North Slope of the USA. Provenience strongly suggests that it is $M$. primigenius. Radiocarbon dated to $41,510 \pm 480{ }^{14} \mathrm{Cya}$ (Beta \#264909, Beta Analytic Inc., Miami, FL, USA). The mitochondrial hypervariable region for this specimen was partially sequenced previously [11] and falls within haplogroup C (haplotype C30). Its exceptional DNA preservation prompted its use in the multiplex experiments.

\section{Sequence acquisition, assembly, and classification}

Procedures were performed at a number of laboratories [45-49]. Detailed descriptions of wet laboratory procedures used for sequence acquisition, as well as laboratory procedures for data assembly, can be found in Additional file 1. Primers were taken from previous publications or newly designed using the Integrated DNA Technologies SciTools OligoAnalyzer 3.1 [50]. Pre-sequencing preservation evaluations were performed following $[24,51,52]$. We used a metagenomic high-throughput sequencing approach to characterize the whole mitochondrial genome of the Huntington mammoth, and multiplex PCR combined with high-throughput sequencing to obtain the whole mitochondrial genome of IK-99-70. We also cloned and sequenced several PCR products from the mammoths, with independent PCR amplification, cloning and sequencing of products from the Huntington mammoth performed at a separate laboratory. We assembled mitochondrial reads with AMOScmp [53] using NUCmer [54] as well as with Geneious 5.1.7 [55] and then visualized assemblies using amosvalidate [56], Hawkeye [57] and Geneious. The Huntington nuclear genome read assemblies were built using these and also classified using PhymmBL [58], comparing previously published WM nuclear genome sequences [59] and the L. africana nuclear genome sequence [60]. Sequence read files for Huntington and IK99-70 are deposited in the NCBI Short Read Archive (SRA) as \#SRP006656. Sanger trace files from Huntington, Union Pacific, and IK-99-70 are deposited in the NCBI Trace Archive as \#TI2306523713-2306523816. Consensus mitochondrial sequences are deposited in GenBank as \#JF912199 (Huntington) and \#JF912200 (IK-99-70). Our assemblies of Huntington, IK-99-70, and Union Pacific reads and traces are available at [61].

\section{Phylogenetic analyses}

Detailed description of phylogenetic analyses performed can also be found in Additional file 1. These explored topological and chronological features of mammoth mitochondrial phylogeny using a Bayesian approach, comparing hundreds of sequences from a number of studies discussed above as well as from [62]. We employed jModelTest v.0.1.1 [63] to choose model parameters and BEAST v.1.5.6 [64] to build trees and estimate coalescent dates, using tip calibration points corresponding to radiocarbon ages of the samples, as well as root calibration points described by [65]. These runs were analyzed in Tracer v.1.3 [66] and trees were visualized with FigTree v.1.3 [67].

\section{Additional material}

Additional File 1: Additional materials and methods. A detailed description of Materials and methods.

Additional File 2: Additional tables. A collection of tables referred to in the text as tables S1 through S7.

Additional File 3: Additional figures. A collection of figures referred to in the text as Figures S1 to S8.

\begin{abstract}
Abbreviations
${ }^{14}$ Cya, Radiocarbon years ago; CM, Columbian mammoth, Mammuthus columbi; ILS, incomplete lineage sorting; MRCA, most recent common ancestor; mtDNA, mitochondrial DNA; PCR, polymerase chain reaction; WM, woolly mammoth, Mammuthus primigenius.
\end{abstract}

\section{Acknowledgements}

We thank the College of Eastern Utah Museum, especially J Bartlett, J Bird, and $\mathrm{R}$ Barlow for providing access to and valuable information regarding the Huntington Mammoth; the University of Wyoming Vertebrate Paleontology Collections, especially M Clementz and B Breithaupt, for providing access to and information regarding the Union Pacific Mammoth; and P Matheus, G Zazula, and D Froese of the Yukon Department of Tourism and Culture for access to IK-99-70. Ambry Genetics provided valuable assistance in experimental design. B Miljour drew the mammoth and elephant images in Figure 2. Funding was provided by the Natural Science and Engineering Research Council (grant \#299103-2004), the Social Sciences and Humanities Research Council (grant \#410-2004-0579), the Canadian Research Chairs program, Discovery Communications (a Quest grant), the National Science Foundation (EAR-0545095 to DF; GRF to JE), the Ontario Graduate Studies programme (scholarship to AD), the University of Utah, the American Museum of Natural History, McMaster University, and Eco-Anthropologie, Muséum national d'Histoire naturelle (UMR 7206). We would like to dedicate this to the late Paul S Martin, a great colleague and friend.

\section{Author details}

${ }^{1}$ McMaster Ancient DNA Centre, Department of Anthropology, McMaster University, 1280 Main Street West, Hamilton, Ontario L8S 4L9, Canada.

${ }^{2}$ Muséum national d'Histoire naturelle, UMR 7206 Eco-anthropologie, Equipe "génétique des populations humaines," 57 rue Cuvier, CP139, 75231 Paris Cedex 05, France. ${ }^{3}$ Center for Bioinformatics and Computational Biology, 3115 Biomolecular Sciences Bldg \#296, University of Maryland, College Park, MD 20742, USA. ${ }^{4}$ Department of Anthropology, University of Utah, 270 S. 1400 East Room 102, Salt Lake City, UT 84112-0060, USA. ${ }^{5}$ Museum of Paleontology and Department of Geological Sciences, University of Michigan, 1109 Geddes Ave, Ann Arbor, Ml 48109-1079, USA. ${ }^{6}$ Division of Vertebrate Zoology, American Museum of Natural History, Central Park West @ $79^{\text {th }}$ St, New York, NY 10024, USA.

\section{Authors' contributions}

$J E, R D, D O, D F, R M$ and HP planned and designed the project. JE, RD, AD and CK performed wet laboratory work. JE, RD, AD, TT, and SS performed assembly and analysis of the sequence data. JE wrote the paper with assistance from all authors.

\section{Competing interests}

The authors declare that they have no competing interests. 
Received: 1 April 2011 Revised: 9 May 2011 Accepted: 31 May 2011 Published: 31 May 2011

\section{References}

1. Maglio V: Origin and evolution of the Elephantidae. Trans Am Phil Soc 1973, 63:31-144.

2. Agenbroad LD: North American Proboscideans: Mammoths: The state of Knowledge, 2003. Quat Int 2005, 126-128:73-92.

3. Harington C: Mammoths, bison and time in North America. In Quaternary Dating Methods. Edited by: Mahaney W. Amsterdam: Elsevier Science Publications; 1984:299-309.

4. Lister A, Bahn PG: Mammoths: Giants of the Ice Age. Revised edition. Berkeley, CA: University of California Press; 2007.

5. Kurtén B, Anderson E: Pleistocene Mammals of North America New York: Columbia University Press; 1980.

6. Lister AM, Sher AV: The origin and evolution of the woolly mammoth. Science 2001, 294:1094-1097.

7. Lister AM, Sher AV, van Essen H, Wei G: The pattern and process of mammoth evolution in Eurasia. Quat Int 2005, 126-128:49-64.

8. Shoshani J, Tassy P: Advances in proboscidean taxonomy \& classification, anatomy \& physiology, and ecology \& behavior. Quat Int 2005, 126128:5-20.

9. Barnes I, Shapiro B, Lister A, Kuznetsova T, Sher A, Guthrie D, Thomas MG: Genetic structure and extinction of the woolly mammoth, Mammuthus primigenius. Curr Biol 2007, 17:1072-1075.

10. Gilbert MT, Drautz DI, Lesk AM, Ho SY, Qi J, Ratan A, Hsu CH, Sher A, Dalen L, Gotherstrom A, Tomsho LP, Rendulic S, Packard M, Campos PF, Kuznetsova TV, Shidlovskiy F, Tikhonov A, Willerslev E, lacumin P, Buigues B, Ericson PG, Germonpre M, Kosintsev P, Nikolaev V, Nowak-Kemp M, Knight JR, Irzyk GP, Perbost CS, Fredrikson KM, Harkins TT, et al: Intraspecific phylogenetic analysis of Siberian woolly mammoths using complete mitochondrial genomes. Proc Natl Acad Sci USA 2008, 105:8327-8332.

11. Debruyne R, Chu G, King CE, Bos K, Kuch M, Schwarz C, Szpak P, Grocke DR Matheus P, Zazula G, Guthrie D, Froese D, Buigues B, de Marliave C, Flemming C, Poinar D, Fisher D, Southon J, Tikhonov AN, MacPhee RD, Poinar HN: Out of America: ancient DNA evidence for a new world origin of late quaternary woolly mammoths. Curr Biol 2008, 18:1320-1326.

12. Nystrom V, Dalen L, Vartanyan S, Liden K, Ryman N, Angerbjorn A: Temporal genetic change in the last remaining population of woolly mammoth. Proc Biol Sci 2010, 277:2331-2337.

13. Enk JM, Yesner DR, Krossen KJ, Veltre DW, O'Rourke DH: Phylogeographic analysis of the mid-Holocene Mammoth from Qagnax Cave, St. Paul Island, Alaska. Palaeogeog Palaeoclimatol Palaeoecol 2009, 273:184-190.

14. Debruyne R, Poinar HN: Time dependency of molecular rates in ancient DNA data sets, a sampling artifact? Syst Bio/ 2009, 58:348-360.

15. Ho SY, Phillips MJ, Cooper A, Drummond AJ: Time dependency of molecular rate estimates and systematic overestimation of recent divergence times. Mol Biol Evol 2005, 22:1561-1568.

16. MacFadden BJ, Hulbert RC Jr: Calibration of mammoth (Mammuthus) dispersal into North America using rare earth elements of PlioPleistocene mammals from Florida. Quat Res 2009, 71:41-48.

17. Gillette DD, Madsen DB: The Columbian mammoth, Mammuthus columbi, from the Wasatch Mountains of central Utah. J Paleontol 1993, 67:669-680.

18. Schaedler JM, Krook L, Wootton JA, Hover B, Brodsky B, Naresh MD, Gillette DD, Madsen DB, Horne RH, Minor RR: Studies of collagen in bone and dentin matrix of a Columbian mammoth (late Pleistocene) of central Utah. Matrix 1992, 12:297-307.

19. Knapp $M$, Hofreiter $M$ : Next generation sequencing of ancient DNA: requirements, strategies and perspectives. Genes 2010, 1:227-243.

20. Krause J, Dear PH, Pollack JL, Slatkin M, Spriggs H, Barnes I, Lister AM, Ebersberger I, Paabo S, Hofreiter M: Multiplex amplification of the mammoth mitochondrial genome and the evolution of Elephantidae. Nature 2006, 439:724-727.

21. Paabo S, Poinar H, Serre D, Jaenicke-Despres V, Hebler J, Rohland N, Kuch M, Krause J, Vigilant L, Hofreiter M: Genetic analyses from ancient DNA. Annu Rev Genet 2004, 38:645-679.

22. Green RE, Krause J, Ptak SE, Briggs AW, Ronan MT, Simons JF, Du L, Egholm M, Rothberg JM, Paunovic M, Paabo S: Analysis of one million base pairs of Neanderthal DNA. Nature 2006, 444:330-336.
23. Noonan JP, Hofreiter M, Smith D, Priest JR, Rohland N, Rabeder G, Krause J, Detter JC, Paabo S, Rubin EM: Genomic sequencing of Pleistocene cave bears. Science 2005, 309:597-599.

24. Schwarz C, Debruyne R, Kuch M, McNally E, Schwarcz H, Aubrey AD, Bada J, Poinar $\mathrm{H}$ : New insights from old bones: DNA preservation and degradation in permafrost preserved mammoth remains. Nucleic Acids Res 2009, 37:3215-3229.

25. Irwin C, Irwin H, Agogino G: Wyoming muck tells of battle: Ice Age vs. Mammoth. National Geographic Society Magazine 1962, 121.

26. McGrew PO: The Rawlins mammoth. Wyoming Geological Society Guidebook 1961, 315-317.

27. Haynes G: Mammoths, Mastodonts and Elephants Cambridge University Press; 1991.

28. Moore WS: Inferring phylogenies from mtDNA variation - mitochondrialgene trees versus nuclear-gene trees. Evolution 1995, 49:718-726.

29. Nyakaana $S$, Arctander P: Population genetic structure of the African elephant in Uganda based on variation at mitochondrial and nuclear loci: evidence for male-biased gene flow. Mol Ecol 1999, 8:1 105-1115.

30. Vidya TNC, Sukumar R: Social organization of the Asian elephant (Elephas maximus) in southern India inferred from microsatellite DNA. J Ethol 2005, 23:205-210.

31. Vidya TNC, Sukumar R, Melnick DJ: Range-wide mtDNA phylogeography yields insights into the origins of Asian elephants. Proc R Soc B Biol Sci 2009, 276:893-902.

32. Rohland N, Reich D, Mallick S, Meyer M, Green RE, Georgiadis NJ, Roca AL, Hofreiter M: Genomic DNA sequences from mastodon and woolly mammoth reveal deep speciation of forest and savanna elephants. PLoS Biol 2010, 8:e1000564.

33. Roca AL, Georgiadis N, Pecon-Slattery J, O'Brien SJ: Genetic evidence for two species of elephant in Africa. Science 2001, 293:1473-1477.

34. Comstock KE, Georgiadis N, Pecon-Slattery J, Roca AL, Ostrander EA, O'Brien SJ, Wasser SK: Patterns of molecular genetic variation among African elephant populations. Mol Ecol 2002, 11:2489-2498.

35. Grubb P, Groves CP, Dudley JP, Shoshani J: Living African elephants belong to two species: Loxodonta africana (Blumenbach, 1797) and Loxodonta cyclotis (Matschie, 1900). Elephant 2000, 2:1-4.

36. Groves CP, Grubb P: Do Loxodonta cyclotis and L. africana interbreed? Elephant 2000, 2:4-7.

37. Debruyne R: A case study of apparent controversy between molecular phylogenies: the interrelationships of African elephants. Cladistics 2005, 21:31-50.

38. Roca AL, Georgiadis N, O'Brien SJ: Cytonuclear genomic dissociation in African elephant species. Nat Genet 2005, 37:96-100.

39. Fisher D: Season of death, growth rates, and life history of North American mammoths. In Proceedings of the First International Conference on Mammoth Site Studies: 11-13 March 1998. Edited by: West D. Lawrence, KS: University of Kansas; 2001:121-135.

40. Shoshani J, Tassy P: The Proboscidea: Evolution and Palaeoecology of Elephants and Their Relatives Oxford; New York: Oxford University Press; 1996.

41. Burbano HA, Hodges E, Green RE, Briggs AW, Krause J, Meyer M, Good JM, Maricic T, Johnson PL, Xuan Z, Rooks M, Bhattacharjee A, Brizuela L, Albert FW, de la Rasilla M, Fortea J, Rosas A, Lachmann M, Hannon GJ, Paabo S: Targeted investigation of the Neandertal genome by arraybased sequence capture. Science 2010, 328:723-725.

42. Maricic T, Whitten M, Paabo S: Multiplexed DNA sequence capture of mitochondrial genomes using PCR products. PLoS One 2010, 5:e14004

43. Allendorf FW, Leary RF, Spruell P, Wenburg JK: The problems with hybrids: setting conservation guidelines. Trends Ecol Evol 2001, 16:613-622.

44. Rhymer JM, Simberloff D: Extinction by hybridization and introgression. Annu Rev Ecol Systematics 1996, 27:83-109.

45. McMaster Ancient DNA Centre. [http://socserv.mcmaster.ca/adna/index. htm].

46. Service de Systématique Moléculaire of the Muséum national d'Histoire naturelle. [http://www.mnhn.fr/mnhn/ssm/index.html].

47. Institute for Molecular Biology and Biotechnology Laboratory. [http:// www.science.mcmaster.ca/mobixlab/].

48. Ambry Genetics. [http://www.ambrygen.com/].

49. Center for Bioinformatics and Computational Biology. [http://www.cbcb. umd.edu/]. 
50. Integrated DNA Technologies (IDT) SciTools OligoAnalyzer 3.1. [http:// www.idtdna.com/analyzer/Applications/OligoAnalyzer/].

51. Poinar HN, Schwarz C, Qi J, Shapiro B, Macphee RD, Buigues B, Tikhonov A, Huson DH, Tomsho LP, Auch A, Rampp M, Miller W, Schuster SC:

Metagenomics to paleogenomics: large-scale sequencing of mammoth DNA. Science 2006, 311:392-394.

52. Deagle BE, Eveson JP, Jarman SN: Quantification of damage in DNA recovered from highly degraded samples - a case study on DNA in faeces. Front Zool 2006, 3:11

53. Pop M, Phillippy A, Delcher AL, Salzberg SL: Comparative genome assembly. Brief Bioinform 2004, 5:237-248.

54. Kurtz S, Phillippy A, Delcher AL, Smoot M, Shumway M, Antonescu C, Salzberg SL: Versatile and open software for comparing large genomes. Genome Biol 2004, 5:R12.

55. Drummond AJAB, Buxton S, Cheung M, Cooper A, Heled J, Kearse M, Moir R, Stones-Havas S, Sturrock S, Thierer T, Wilson A: Geneious v5.1. [http://www.geneious.com/].

56. Phillippy AM, Schatz MC, Pop M: Genome assembly forensics: finding the elusive mis-assembly. Genome Biol 2008, 9:R55.

57. Schatz MC, Phillippy AM, Shneiderman B, Salzberg SL: Hawkeye: an interactive visual analytics tool for genome assemblies. Genome Biol 2007, 8:R34.

58. Brady A, Salzberg SL: Phymm and PhymmBL: metagenomic phylogenetic classification with interpolated Markov models. Nat Methods 2009, 6:673-676.

59. Miller W, Drautz DI, Ratan A, Pusey B, Qi J, Lesk AM, Tomsho LP, Packard MD, Zhao F, Sher A, Tikhonov A, Raney B, Patterson N, LindbladToh K, Lander ES, Knight JR, Irzyk GP, Fredrikson KM, Harkins TT, Sheridan S, Pringle T, Schuster SC: Sequencing the nuclear genome of the extinct woolly mammoth. Nature 2008, 456:387-390.

60. Public FTP Server at the Broad Institute housing the Loxodonta africana nuclear genome. [http://www.broadinstitute.org/ftp/pub/assemblies/ mammals/elephant/loxAfr3/].

61. Public FTP server at $C B C B$ storing various datafiles associated with this manuscript. [ftp://ftp.cbcb.umd.edu/pub/data/mammoth/].

62. Rogaev El, Moliaka YK, Malyarchuk BA, Kondrashov FA, Derenko MV, Chumakov I, Grigorenko AP: Complete mitochondrial genome and phylogeny of Pleistocene mammoth Mammuthus primigenius. PLoS Biol 2006, 4:e73.

63. Posada D: jModelTest: phylogenetic model averaging. Mol Biol Evol 2008 , 25:1253-1256

64. Drummond AJ, Rambaut A: BEAST: Bayesian evolutionary analysis by sampling trees. BMC Evol Biol 2007, 7:214.

65. Rohland N, Malaspinas AS, Pollack JL, Slatkin M, Matheus P, Hofreiter M: Proboscidean mitogenomics: chronology and mode of elephant evolution using mastodon as outgroup. PLOS Biol 2007, 5:e207.

66. Rambaut A, Drummond A: Tracer v1.3. [http://tree.bio.ed.ac.uk/software/ tracer/].

67. FigTree v1.3. [http://tree.bio.ed.ac.uk/software/figtree/].

doi:10.1186/gb-2011-12-5-r51

Cite this article as: Enk et al:: Complete Columbian mammoth

mitogenome suggests interbreeding with woolly mammoths. Genome Biology 2011 12:R51.

\section{Submit your next manuscript to BioMed Central and take full advantage of:}

- Convenient online submission

- Thorough peer review

- No space constraints or color figure charges

- Immediate publication on acceptance

- Inclusion in PubMed, CAS, Scopus and Google Scholar

- Research which is freely available for redistribution

Submit your manuscript at www.biomedcentral.com/submit
Biomed Central 